\title{
Study on the Achievements of Chinese Representational Painting and Its Contemporary Enlightenment
}

\author{
Yuan Chen ${ }^{1}$ and Anqi Chen ${ }^{2}$ \\ Huaibei vocational and technical college (China Anhui235000) ${ }^{1}$ \\ Guangdong Baiyun University (China Guangdong 235000) ${ }^{2}$
}

Fund project in 2016 anhui provincial higher school teaching quality engineer (master) studio project "liu yong studio" (2016msgzs065)

Chen Yuan. Male. Han .February Born in Hefei, Anhui, in February 1964 . Graduated from the Arts Department of Huaibei Normal University and received a Bachelor of Arts Degree. The China Academy of Art oil painting department third studio (figurative performance painting) won a master's degree in literature. Now a member of the Chinese Artists Association. A national artist. Research direction: The field of contemporary representational representation and painting.

Chen Anqi. Female. Han .Born in Huaibei, Anhui, in 1988.Graduated from Guangzhou Acmdemy of Fine Arts and received a master's degree in art. Lecturer

Keywords: Chinese representational painting; Achievements; Inspiration

\begin{abstract}
The development of representational expressive art in China has led to the transformation of basic methodology of painting. Although it had conflict on traditional painting consciousness, it was also accepted by a group of artists with advanced thoughts and artistic sensitivities. Based on the current situation of the development of representational painting, first analyzes the basic connotation and the artistic pursuit of characteristics, and then introduces the representational painting theory in China achievements, according to the above content, makes judgment for the development tendency of contemporary representational painting, and it also hopes to Chinese representational painting and improve the level of creating conditions.

With the development of cultural globalization, the current world on the definition of art has become increasingly blurred, whether it is from the traditional concept or content or media, gradually towards diversification and comprehensive development, and everyone is an artist who has gradually become a trend. Now, contemporary art has exposed the cruelty, and the age of high tech image has been overflowing, it can't be sure where is the painting meaning, this is placed in front of a Chinese artist with a sense of profound thinking and historical mission which includes Chinese contemporary representational paintings. In order to further analyze the development achievements of Chinese representational painting and the enlightenment for the whole art field, we must first recognize the basic connotation and artistic pursuit of representational expressive painting.
\end{abstract}

\section{Part One the Basic Connotation and Artistic Pursuit of Representational Painting}

"Representational Expressionism" was originated from France in the last 70s, and the theory of painting has a background and tendency of phenomenology, in the last century in $90 \mathrm{~s}$, it was brought into the mainland of China by the Chinese French painter and art theorist Stuart Li. The original "representational painting" which is a unique vocabulary was used to describe a number of Europe "painter", (1) such as Jacques May Siti, Morandi, Moriyama, Arica, Raymond Masson and so on, and the representational painting is the inheritance and development of a spirit of western traditional painting and the combination of contemporary art and philosophy with painting that against the abstract art to promote the use of phenomenological point of view to see all things in the world, and it can go out to a middle of the road, while it is not a style, not a painting form, and it is not a doctrine, but it is a painter's way of viewing and attitude which shows a persistent exploration of the existence of the artist, nature, history, nationality, destiny theme and deep thinking with the characteristics of ideas and originality. With the introduction of the representational painting 
methodology into China, its unique philosophical and painting theories resonate with many Chinese oil painters. Because of the great difference between western culture tradition and Chinese culture tradition, there is a big difference between the introduction of concretion method and the methodology of painting. It mainly lies in the form of expression, the theme of the artistic content, and the Chinese spirit and ideological features of the painter. Compared with other realistic paintings, expressive paintings and abstract paintings in China, the difference between Chinese contemporary representational and expressive paintings is that it is not satisfied with the traditional painting of the tracing of nature, and it is not the subjective feeling of the whole factors and not peel with no reality whatever things themselves, but to promote to go back to the primary visual and authentic, where there is the presence of "things" and there is "I", and this can achieve the "blending" that has the same meaning with China culture in savouring images. The methodology of representational expressionism emphasizes the cooperation between eyes and mind, intuition and reason, and it connects Chinese and Western cultures by trying to get out of a way of visual thinking on shelf painting which provides a brand new inspiration for contemporary art of painting. In recent years, with the continuous development of modern materialism and the western scientific knowledge learning in modern times that was born out of a group of pioneering writers of Figurative Expressionism, they earnestly study and observe the western painting works, through the integration of development and the creation of many excellent works and it has opened up a new way for the field of contemporary painting and art in our country.

\section{Part Two the Development and Achievement of Representational Painting Theory in China}

Stuart Li, a famous French Chinese artist and theorist, opened an oil painting course in The China Academy of Art in 1991, and for the first time, he implemented the basic methodology of representational expression in China, and laid the foundation for the development of the theory of representational expressive painting in China. After twenty years of development, at present, the theory of representational expressionism has been widely concerned and studied by experts, scholars and oil painting majors in Academy of Fine Arts. It has a subtle influence on the theory and creation of oil painting from aspects of painting theory or creation. (2) for a long time, the creation and teaching of Chinese oil painting art are deeply influenced by the education of the Soviet school. For a group of artists who are strong and influential in traditional arts, it is very difficult for them to change the way of watching and the expression of techniques. Although scholars in recent years have full confidence and expectation in the development of the theory of representational expressive painting in China, many scholars have expressed concern about the theory of representational painting, including the conflict between old and new ideas and the contents of thinking and borrowing.

In order to better analyze the development achievements of representational painting theory in China, it is inseparable from the following representative case analysis of the leading figures of contemporary Chinese representational painting, which includes Jiang Xu, Canjun Yang, Xiaojian Jiao and Xiaoming Zhang. They actively explore through practice of representational painting methodology in succession which were based on Chinese cultural tradition and phenomenology, not only in the study of the theory and practice of painting that has made brilliant outstanding achievement, and it is a major breakthrough in the essence of art works. Among the many painters, Yang is the most representative. As the latest generation of representational painting representatives, his theory of artistic creation and experience perfection was just perfect, and this is vividly shown in his works, in his early works, such as the Six Gentleman, The Nanjing Massacre and later Miaonv all reflect the basic skills and the historical painting of the monument of the control ability, but also shows a narrative, illustrative painting pursuit. At the end of last century, Yang joined the army for many years to abandon the painting method and put it into the research and practiced in the concretion of expression theory on painting. After nearly 20 years of creative practice, In addition, some works of Yang also showed a subtle color on the images of the control and picture structure unique to series of Fish, series of Portrait and series of the Scenery of Home. These works show Yang's understanding of the theory of representational expressive painting, and also show the 
painter's visual thinking and his deep accomplishment in Chinese culture. (3)Canjun Yang is a leader in the field of oil painting landscape painting figures, the love speak a natural implicit style cover in the "real" in the process of painting landscape works, the performance for the tranquil and natural images and highlight the traditional landscape painter for Chinese reference and fusion art can have an irreplaceable role. The painter Xiaojian Jiao's works are mostly in a random state, which may be a single person in daily life, or is the traditional sense of creation, weakening the product, or the artist's own is the cultural salvation. No matter what kind of painting content and subject matter, Xiaojian Jiao likes to pursue visual knowledge in the process of painting, so as to express the philosophical spirit behind things, so as to highlight the expressive power of works.

The Chinese painting circles are in the critical stage of transformation. That's when the culture conflict and the fusion of technology bring up excellent masters of painting. Through these open mind, art is behind the discussion and practice of contemporary artists, Chinese representational painting theory is able to practice and development, which is not only the traditional art spirit of mutual financing, so as to optimize the education and the whole field of painting to create the conditions. In addition, the representational painting works of contemporary China that can fully in the light of the work performance of the latent semantic and continuously add flaws and neglect specific painting theory, and it is closer to the true art which also has a practical significance.

\section{Part Three Contemporary Apocalypse of Chinese Representational Painting}

Representational painting is the epitome of the development of modern painting field. It not only gradually becomes an invaluable part of China's art and humanity philosophy, but also meets all kinds of favorable development factors. It has realized the accommodation of traditional culture and foreign culture, and has achieved teaching reform and ideological development by way of mutual reference and promotion. This is of great realistic value and significance for the contemporary Chinese representational performance presenting a more unique Chinese style. A number of contemporary Chinese representational painting painters have made great achievements in the exploration and development for more than twenty years. At the same time, they also provide strong evidence for the development of the theory in China, and prove their vitality in China.

With the continuous extend of representational painting, figurative painting works of contemporary China writers also gradually towards the normalization of the direction of development, while a fruit, a potted plant, indoor space, the scenery and portrait and so on can be observed as the direction of the painting experience.(4)From the painting material and content to achieve a breakthrough, it also has great practical significance to reflect the ultimate meaning of life and care, especially in the painting on time reflects the basic attribute of human society and the situation of reflection of human existence, which is the development of China art, and is the human field of Humanities and Social Sciences progress. At present, our country is in the period of social and economic transformation, the construction of modernization can not be separated from advanced science and technology, at the same time, it can not be separated from the development and inheritance of culture. The reality of social reality reflected in the history of art will no longer be ideal. It is the main basis for us to inherit and develop the culture. Despite the limitations of the times, the aesthetic aspects of abstract visual China's national overall quality is still lacking, especially with the relationship among people, people and society are constantly changing, the traditional values were challenged, it will also affect the development of representational painting. So we still need to firmly develop our footsteps and recognize the fusion relationship between traditional culture and foreign cultures, so as to create conditions for better publicizing traditional culture and enhancing the characteristics of national culture.

\section{Conclusion}

To sum up, the Chinese representational painting has achieved remarkable progress after decades of development. It has achieved good results in both the overall level of painting and the expansion of ideology. With the development of China's achievements and characteristics of representational 
painting, it still has a certain gap with Western representational painting art and theoretical level in the process of development in the new era should also continue to strengthen the integration of painting and traditional Chinese representational painting art form, and it will continue the traditional culture and the unique painting art which has the combination of form, and create the representational painting works with Chinese characteristics, so as to lay a good foundation and conditions for the inheritance and development of traditional culture.

\section{Reference}

[1] Zhiqun Yang. A brief analysis of the localization process of the expressive painting language of Chinese oil painting[D].Shandong Normal University,2016.

[2] Zhi Zhou. The representational painting and the Unfettered Tour from the perspective of Phenomenology[J].Journal of Yancheng Institute of Technology (Social Science),2014,27(03):78-81.

[3] Jian Zhang. Study on the fusion of the representational expressionism oil painting and the spirit of Chinese traditional painting[J].Journal of Zhejiang Business Technology Institute,2014,13(02):39-41.

[4] Condensation of visual images. A special exhibition of representation and painting in France and China[J].Art Literature,2012(04):72-73.

[5] Yulong Liu. Chinese representational painting and its closest to the traditional culture[J].Literature and Art Research,2012(06):158-159. 